\title{
ASPECTOS PALEOCLIMATICOS REFLETIDOS EM ESPECIMES LENHOSOS GONDWANICOS DO BRASIL ${ }^{1}$
}

Lucia Montilla Mayer ${ }^{2}$

RESUMO

São abordados, neste trabalho, aspectos anatômicos de lenhos gimnospérmicos gondwânicos, coletados em afloramentos da Formação Rio Bonito, no Estado de Santa Catarina, Permiano da Bacia do Paraná, que refletem condições paleoclimáticas predominantes, inferidas, principalmente, com base no desenvolvimento lenhoso e em parâmetros de "sensibilidade anual" e "sensibilidade média". Do ponto de vista sistemático, leva-se em conta apenas, um posicionamento amplo das associações estudadas, dentro das gimnospermas, sem a necessidade de classificação específica.

\section{ABSTRACT}

This paper presents a study of anatomic features of fossil gymnospermous woods from the Gondwana of Brazil, which reflect paleoclimatic dominant conditions, on the basis of the average of annual and mean sensitivity expressed on the wood-growth development.

The woods are related to the coal flora and were collected in outcrops of the Rio Bonito Formation bellow the main coal measures, Permian of the Paraná Basin, Santa Catarina State, south of Brazil.

\section{INTRODUÇAO}

Os exemplares de lenhos silicificados aqui estudados, sob os aspectos anatômicopaleoclimático, foram coletados pela autora, em 1984 e 1986, em duas áreas de afloramento da Formação Rio Bonito, Supergrupo Tubarão, Permiano Médio a Superior da Bacia do Paraná, no Estado de Santa Catarina. A primeira área situa-se na localidade de Rio da Estiva, km 33 da rodovia BR 116, trecho Mafra-Papanduva, onde os espécimes foram coletados no arenito cinzaesbranquiçado, friável, de granulação média e fina, com estratificação cruzada acanalada, sotoposto à sequência mais fina, de siltitos, folhelhos e argilitos, com intercalações delgadas de siltito carbonoso e carvão, ricos em vegetais (glossopterídeas, partes de caules e sementes, parcialmente incarbonizados) considerados por ROSLER (1975) como uma variação da "tafoflora C" (ROSLER, 1978). Esse arenito constitui o topo do membro inferior ou Membro Triunfo (SCHNEIDER et al., 1974), da Formação Rio Bonito. Também dessa localidade, procede a forma vertebrarióide Schopfcaulia peripaludica Mussa, 1982. A segunda área situa-se a aproximadamente $4,5 \mathrm{~km}$ ao norte da cidade de Salete, onde afloram arenitos amarelados, de granulação média a grossa, com nível feldspático, estratificação cruzada acanalada, sobrepostos aos arenitos de influência marinha rasa, com fauna de invertebrados marinhos, típica de Taió e que também ocorre em Rio do Sul, Rio do Oeste e outras localidades na região

1 Contribuição ao Projeto no 237: Floras dos continentes gondwânicos - PICG.

2 Departamento Nacional da Produção Mineral - DGM 
central de Santa Catarina. Por estarem, estes arenitos, sobrepostos ao nível marinho, sua deposição se deu já em fase regressiva, quando a drenagem fluvial se desenvolvia na área litorânea emersa, estratigraficamente. Esse intervalo corresponderia à transição do Membro Paraguaçu para a base do Membro Siderópolis (SCHNEIDER et al., op. cit.), da Formação Rio Bonito (Fig. 1).

Os exemplares abordados nesta avaliação paleoclimática foram investigados tentativamente, considerando-se a validade da aplicação das expressões de A.E.DOUGLAS (1928) para "sensibilidade média" e classificação de seqdências de anéis dos lenhos como característicos de espécimes "sensíveis" ou "tolerantes". Avaliação estatística de medidas de variação no crescimento lenhoso anual é a base do trabalho da dendroclimatologia, mas cumpre considerar as dificuldades que se somam num trabalho dessa natureza, na medida que caminhamos para trás, no tempo geológico, e tentamos considerar espécimes paleozóicos, no caso presente, do Permiano, quando a frequência de ocorrência de espécimes por afloramento, se reduz e o estado de preservação, em geral, se mostra bem mais precário.
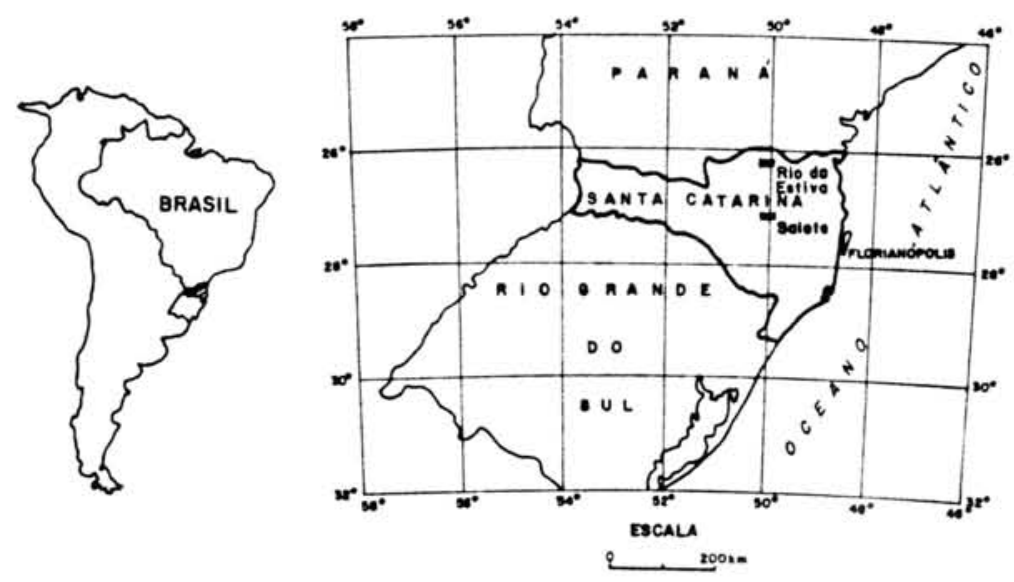

Fig. 1 - Mapa de situação geográfica das localidades fossiliferas.

\section{METODOS E CRITERIOS}

Foram estudados os espécimes seguintes, depositados nas coleções paleobotânicas do Museu Nacional /UFRJ e do DNMP (DGM-Seção de Paleontologia), ambas no Rio de Janeiro: 5 espécimes (MN 1.561-Pb; MN 1.562-Pb; MN 1.563-Pb; MN 1.564-Pb e DGM 1.837-Pb) da localidade de Rio da Estiva e 5 espécimes (MN 1.588-Pb; MN 1.589-Pb; MN 1.590-Pb; DGM 1.835-Pb; DGM 1.839-Pb) do afloramento situado ao norte de Salete. Os exemplares foram serrados e das seções obtidas foram preparadas lâminas do tipo petrográfico, com orientações transversais, radiais e tangenciais, em relação à direção de crescimento longitudinal dos lenhos. A partir das lâminas, foi feito estudo anatômico visando o posicionamento sistemático geral e interpretação dos aspectos paleoclimáticos, por medições dos anéis de crescimento anual, sempre considerados em pares consecutivos e variações na sua estrutura.

Foram aplicadas as fórmulas de DOUGLAS (1928) para 
Bol. IG-USP, Publ.Esp., 7:89-99, 1989

$$
\begin{aligned}
& \text { Sensibilidade anual }=\frac{2\left(x_{t+1}-x_{t}\right)}{\left(x_{t+1}+x_{t}\right)} \cdot . \\
& \text { Sensibilidade média }=\frac{1}{n-1} \cdot \sum_{t=1}^{t=n-1} \frac{2\left(x_{t+1}-x_{t}\right)}{x_{t}+x_{t+1}} ;
\end{aligned}
$$

onde: $x$ é largura do anel;

$t$ é o $n$ 의 do ano do anel;

n é o no de anéis considerados na sequência.

Resultados de "sensibilidade média" superiores a 0,3, por convenção, traduzem espécimes sensitivos e valores inferiores a 0,3 traduzem espécimes tolerantes ou complacentes.

T.H. JEFFERSON, em 1982, aplicou efetivamente, essas expressões para lenhos coletados em florestas fósseis do Cretáceo Inferior da Ilha Alexandre, na Antártica, encontrando valores muito altos, tanto para "sensibilidade média", como para as taxas de crescimento dos anéis, que não correspondiam às condições climáticas das latitudes propostas para a Antártica, durante o Cretáceo.

A avaliação e interpretação dos anéis de crescimento de um espécime lenhoso fossilizado requer cuidados e critérios específicos; que vão desde a identificação precisa de anéis anuais verdadeiros até a observação acurada de variações de larguras em pares consecutivos e variação de espessura das paredes das células que constituem os traqueídeos, ou seja, quaisquer variações morfo-anatômicas no corpo vascular.

No decorrer do processo de fossilização, desde a etapa logo após a morte do vegetal, ocorre a acentuada desidratação dos tecidos e a permineralização pelas soluções percolantes, enquanto o ciclo sedimentar prossegue, com o aumento de carga da deposição dos sedimentos. Em consequência, frequentemente, espécimes sofrem deformações, maiores ou menores, distorções na sua estrutura lenhosa, afetando a conformação das células e dos anéis de crescimento, por vezes, assumindo aspecto de compressão e amarfalhamento. Faz-se necessário, então, reconhecer os verdadeiros anéis delimitados pela mudança da espessura das paredes celulares e da amplitude do lúmen, desde os níveis mais delgados do lenho inicial, até os mais espessos, do lenho final, complementando um ciclo cie crescimento anual (Est. I, Fig. 3 ). E comum a presença de "falsos anéis" decorrentes, na maioria, das condições ambientais acima, ou mesmo de fatores ambientais de variação brusca, durante a vida da planta, mas esses podem ser reconhecidos, em comparação com o padrão de estrutura geral do lenho e porque, normalmente, são descontínuos, no contorno do corpo vascular, aparecendo como feição localizada (Est. I, Fig. 2).

0 chamado "lenho de reação", que é o desenvolvimento assimétrico do corpo vascular, por acréscimo, numa dada área, apenas do cilindro lenhoso, também deve ser identificado. A formação de "lenho de reação" costuma ser uma resposta a fatores que afetam o hábito do vegetal, torções ou envergamentos impostos, plantas arbustivas-trepadeiras, que normalmente se contorcem buscando o equilíbrio de sustentação.

E extremamente interessante o trabalho de PAGE (1970) no qual são feitas datações de episódios de falhamentos geológicos pelos efeitos causados nos anéis de crescimento de árvores viventes, em bosque adjacente à falha de Fairweather no sudoeste do Alaska, E.U.A., na movimentação de 1958. Tais efeitos nos anéis são consequência, principalmente, de torções bruscas, pelos abalos e mesmo seç̧ão dos troncos e ramos, quando então a planta passa a desenvolver o "lenho de reação" assimétrico, bem como de mudanças bruscas no suprimento de água no solo, pelas alterações nos lençóis freáticos, devido à movimentação da falha, que se 
refletem na estrutura celular dos anéis. Pode-se concluir que, se tais fatos são evidentes nas vegetações atuais, também podem estar registrados nos lenhos dos espécimes fósseis, do passado geológico.

\section{DISCUSSAO E RESULTADOS OBTIDOS}

As secções de troncos das duas localidades estudadas possuem região medular parenquimática, parcialmente preservada, em 8 dos 10 exemplares; provida de sistemas de canais em 2 dos exemplares (MN 1.588-Pb; Est. I, Fig. 1 e DGM 1.835-Pb) (MAYER, 1986), COrpo lenhoso livre de parênquima e de estruturas secretoras, com distinção de anéis de crescimento mais nítida nos espécimes da localidade de Rio da Estiva do que nos demais; padrões de pontuações areoladas (Est. II, Fig. 3) das paredes radiais dos traqueídeos, do tipo "araucarióide" (por vezes multisseriadas com contornc hexagonal), predominando disposição alterna, enquanto que nos campos de cruzamento vêem-se pontuações "phyllocladóides" (Est. II, Fig. 2; DGM 1.839-Pb) e "agathióides" (MN 1.590-Pb); os raios medulares são sempre unisseriados, predominando os mais baixos, com 1 a 3 níveis de células (Est. II, Fig. 4), podendo ocorrer alturas de 18 a 22 níveis (GREGUSS, 1955; 1967). Essas feições anatômicas nos permitem situar as duas associações lenhosas, em pauta, como Gymnospermae, dentre as quais pudemos identificar os morfo-gêneros Damudoxylon Maheshwari, 1966; Polysolenoxylon Kräusel \& Dolianiti, 1958 e Protophyllocladoxylon Kräusel, 1939.

Foram os seguintes, os valores obtidos para S.M. ("sensibilidade média"), calculados a partir das "sensibilidades anuais", para cada espécime:

Rio Estiva

\begin{tabular}{|c|c|}
\hline $\mathrm{MN} 1.561-\mathrm{Pb}$ & $\ldots \ldots$ S.M. $=0,68$ \\
\hline $\mathrm{MN} 1.562-\mathrm{Pb}$ & S.M. $=0,90$ \\
\hline $\mathrm{MN} 1.563-\mathrm{Pb}$ & $=0,20$ \\
\hline $\mathrm{MN} 1.564-\mathrm{Pb}$ & S.M. \\
\hline MN $1.837-\mathrm{Pb}$ & $\ldots \ldots$ S.M. $=0,17$ \\
\hline
\end{tabular}

Salete

$$
\begin{aligned}
& \text { MN 1.588-Pb } \ldots \ldots \ldots \ldots \ldots \text { S.M. }=0,31 \\
& \text { MN 1.589-Pb } \ldots \ldots \ldots \ldots \ldots \text { S.M. }=0,40 \\
& \text { MN } 1.590-\mathrm{Pb} \ldots \ldots \ldots \ldots \text { S.M. }=0,25 \\
& \text { DGM 1.835-Pb ......... S.M. }=0,55 \\
& \text { DGM 1.839-Pb } \ldots \ldots \ldots \ldots \ldots \text { S.M. }=0,35
\end{aligned}
$$

Estes valores mostram que os espécimes da associação de Rio da Estiva podem ser ditos mais sensiveis (tres valores acima de 0,3 e dois deles bem mais altos), enquanto que os espécimes da associação de Salete se mostram mais tolerantes, com valores mais próximos de 0,3 . Foram observados, nitidamente, anéis de crescimento mais conspícuos e mais estreitos, além da transição mais brusca, do lenho inicial, para o lenho final, nos elementos de Rio da Estiva, e essas características se mostram menos acentuadas, mais gradacionais, em anéis mais amplos, nos elementos de Salete.

Dados sobre paleomagnetismo e paleogeografia para o Paleozóico da Bacia do Paraná são extremamente escassos. CREER (1967) considera que a América do Sul ocupou altas latitudes, estando próxima ao Polo Sul, no intervalo do Devoniano ao Carbonífero, o que também é demonstrado pelos depósitos glaciais do Supergrupo Tubarão, que, entretanto, parece não conter "memória" paleomagnética suficientemente registrada. Teria migrado rumo ao norte já durante a 
deposição dos Grupos Passa Dois (deposição de "red beds" Corumbataí) e São Bento. 0 autor sugere que durante o tempo "Corumbataí" a latitude da parte sul do Brasil deveria ser cerca de $6^{\circ}$ mais alta que a atual, o que equivaleria aprnximadamente a $30^{\circ} \mathrm{s}$, e seria bem maior para o "tempo Tubarão".

Dos trabalhos mais gerais, que tentam apresentar mapas paleogeográficos do Gondwana, KING (in PLUMSTEAD, 1973) situa o sudeste da América do Sul, durante o Permiano, entre os $60^{\circ} \mathrm{S} e$ $70^{\circ} \mathrm{S}$ e várias modificaç̃es para as suas concepções já foram introduzidas, nos anos seguintes. BAIN (1967) expõe o conceito de que o sul da América do Sul, da India e da Antártida, antes situadas em latitudes mais altas, podem ter sido trazidas para latitudes próximas dos $30^{\circ} \mathrm{S}$ a partir do Permiano. Porém, considera que a distribuição das terras e as correntes marinhas foram mais efetivamente responsáveis pelos efeitos de aquecimento do clima. Associa, ainda, o desenvolvimento de anéis de crescimento, nos espécimes arbóreos, à perda das folhas na estação seca, mais como consequência de importante decréscimo da umidade do que a clima muito frio. Para o período Permiano, esse autor aceita um clima frígido, generalizado, apenas até o Sakmariano, amenizado, progressivamente, passando de frio a mesotermal no KazanianoTartariano, quando já ocorrem os "red beds" no sul do Brasil e Argentina. BRIDEN (1967) apresenta evidências de quatro episódios distintos de "drift" para o Gondwana, datados no Devoniano Médio, Carbonífero Superior, Permiano Superior ao Triássico Inferior e Cretáceo Superior, quando a parte sul da Bacia do Paraná estaria em torno de 305. VOLKHEIMER (1967) apresenta um panorama para a evolução paleoclimática do Gondwana na Argentina e relações com outras regiões integrantes do paleocontinente. Neste trabalho, a regiåo sudeste do Brasil (Bacia do Paraná) é posicionada à latitude de $65^{\circ} \mathrm{S}$ no Paleozóico Superior passando a $40^{\circ} \mathrm{S}-50^{\circ} \mathrm{S}$ já no Permiano Superior (Grupo Passa Dois), com clima variando do glacial (terras mais altas Fm. Itararé), temperado (nas terras mais baixas - camadas de carvão - Fm. Rio Bonito), a cálido, com aridez sazonal, no final do Permiano (calcários do Grupo Passa Dois).

HABICHT (1980) enfatiza a necessidade do uso do "princípio do uniformitarismo" nas interpretações paleoclimáticas, quando se usa dados da flora e fauna e reporta-se aos ambientes formadores de turfas, de hoje, futuros depósitos de carvão que refletem climas úmidos. Porém, para deduções sobre temperatura, requerem-se dados associados à paleobotânica. Em nossa bacia carbonífera de Santa Catarina, temos a flora Glossopteris (toda a associação) relacionada, que evidencia temperaturas amenas a cálidas nas formas latifoliadas mas, paralelamente, indica sazonalidade na sua provável carac terística decídua. Nos mapas de paleoclimas e paleolatitudes propostos por HABICHT (op. cit.) para o período Permiano, vê-se o paleoparalelo de $60^{\circ} \mathrm{S}$ passando aproximadamente na faixa que corresponderia hoje à divisa Santa Catarina-Rio Grande do Sul. Mostra, graficamente, a formação de depósitos de carvão mais freqlentes, entre as paleolatitudes de $50^{\circ} \mathrm{S}$ a $75^{\circ} \mathrm{S}$ para o Gondwana e entre os $30^{\circ} \mathrm{N}$ e $60^{\circ} \mathrm{N}$ para os continentes do Hemisfério Norte.

Considerando que os espécimes estudados provêm de sedimentos da Formação Rio Bonito, estratigraficamente, abaixo das camadas de carvão economicamente mais importantes e acima dos últimos depósitos glaciais do Grupo Itararé, reconhecemos no nosso material, o reflexo desta transição de amenização climática, em suas características morfo-anatômicas, conforme concluímos, a seguir.

\section{CONCLUSOES}

Pudemos verificar a validade da aplicação das expressões de A.E.DOUGLAS (1928), para se chegar aos valores de "sensibilidade anual" e "sensibilidade média", mesmo para um número mais reduzido de espécimes e com menor extensão de lenho preservado, já que os valores obtidos concordam com as demais evidências climáticas para o intervalo estratigráfico em pauta. 
Os valores obtidos para as associaçð̃es das duas localidades refletem uma leve variação climática, do nível de Rio da Estiva (Kunguriano) para o nível de Salete (Kunguriano/Kazaniano). Esta variação indica aumento de umidade no clima, provável elevação de temperatura e, principalmente, diminuição da nitidez de sazonalidade, da primeira para a segunda localidade, refletidos na mudança do aspecto mais denso dos lenhos de Rio da Estiva, com larguras menores de anéis anuais, paredes dos traqueídeos mais espessas e transição do lenho inicial para o lenho final bem marcante, últimas fileiras do lenho final, bem espessadas, com lúmen das células muito reduzido. Já nos espécimes de Salete, o corpo lenhoso é mais amplo em cada anel, constituído de traqueídeos com paredes mais delgadas, indicando estações de crescimento mais prolongadas e a passagem do lenho inicial para o lenho final se faz menos conspícua, mais gradacional.

Salientamos que preferimos interpretar a transição dos anéis anuais de crescimento, com a diminuição das células e espessamento das paredes do lenho final e novo adelgaçamento e aumento das células, na formação do lenho inicial, sucessivamente, devido bem mais à sazonalidade em função da variação da umidade (índices de pluviosidade maiores na estação de crescimento primavera/verão - e bem reduzidos na estação de dormência), do que de temperaturas, existindo, seguramente uma estação seca.

Pela avaliação das paleoflórulas lenhosas do Permiano da Bacia do Paraná, que temos feito (principalmente Formação Rio Bonito), fazemos restrições às propostas de paleolatitudes altas, entre $60^{\circ} \mathrm{S}$ e $70^{\circ} \mathrm{S}$, para a porção sudeste brasileira, da Bacia do Paraná. Vegetação lenhosa, de porte arbóreo, constituída de Gymnospermae, associada a espécies latifoliadas, provavelmente decíduas (como a flora Glossopteris), não ocorre atualmente, em latitudes tão altas, mas formando as florestas temperadas entre $35^{\circ} \mathrm{e}$, no máximo, $55^{\circ}$ de latitude. As atuais florestas frias de coníferas ou "taiga", com folhagem em agulhas, quase totalmente perene, caracterizada pela homogeneidade, é que se desenvolvem, hoje, em latitudes de $55^{\circ} \mathrm{e}$ $60^{\circ}$, seguindo-se a vegetação rasteira, de tundra, a partir dessas latitudes, na faixa dos círculos polares. As florestas frias de coníferas suportam temperaturas durante 0 ano, entre $-6^{\circ} \mathrm{C}$ e $-50^{\circ} \mathrm{C}$, com apenas 1 mês de temperaturas positivas, entre $10^{\circ} \mathrm{C}$ e, no máximo, $16^{\circ} \mathrm{C}$. Se, no passado geológico, as condições climáticas foram semelhantes, nestas altas latitudes, seguramente, tais condições não proporcionariam um desenvolvimento de corpo lenhoso como observamos em nossos espécimes. Assim, concordamos bem mais com a proposição de VOLKHEIMER (1967), de paleolatitudes para a Bacia do Paraná, no Permiano, entre os $40^{\circ} \mathrm{S}$ a $50^{\circ} \mathrm{S}$. Consideramos o "intervalo Rio Bonito" como um tempo de gradação paleoclimática, saindo de condições frias, para mais cálidas, com estações bem marcadas e periodo mais seco.

Finalmente, registramos que espécimes com canais secretores amplos na região medular, de origem lisígena, com possível secreção muscilaginosa, como nos dois espécimes que coletamos em Salete, ainda não foram encontrados no nível de Rio da Estiva. Ainda os espécimes com características "phyllocladóides", que guardam afinidades com a familia Podocarpaceae, hoje distribuídas, predominantemente, na zona temperada, porém úmida do Hemisfério Sul (e em várias áreas associadas a Araucariaceae), também, até o presente, só foram registrados, do nível estratigráfico de Salete para o topo do Permiano.

\section{AGRADECIMENTOS}

Expressamos nossos agradecimentos a Dra. Norma Maria da Costa Cruz, ao Dr. Luiz Victor Baudouin e à Dra. Maria Eugênia C.M. Santos (CPRM-Rio de Janeiro), por toda colaboração na obtenção das fotomicrografias deste trabalho. 
Bol. IG-USP, Publ.Esp., 7:89-99, 1989

\section{REFERENCIAS BIBLIOGRAFICAS}

BAIN, G.W. (1969) Climatic zone patterns through the ages. In: IUGS SYMPOSIUM. GONDWANA STRATIGRAPHY, Buenos Aires, 1967. Paris, Unesco. p. 651-671.

BIROT, P. (1965) Les formations végétales du globe. Paris, Société d’Edition d’Enseignement Supérieur. 508 p.

BRIDEN, J.C. (1969) Intercontinental correlations based on paleomagnetic evidence for recurrent continental drift. In: IUGS SYMPOSIUM. GONDWANA STRATIGRAPHY, Buenos Aires, 1967. Paris, Unesco. p. 421-439.

CREER, K.M. (1969) Paleomagnetic measurements on rocks from the Passa Dois \& São Bento series from Southern Brazil. In: BIGARELLA, J.J.; BECKER, R.D.; PINTO, I.D. Problems in Brazilian Gondwana Geology. 1967. Curitiba. p.303-317.

GREGUSS, P. (1955) Identification of living gymnosperms on the basis of xylotomy. Buddapest, Akadémiai Kiadó. 263 p., 350 pl.

GREGUSS, P. (1967) Fossil gymnosperm woods in Hungary from the Permian to the Pliocene. Budapest, Akadémiai Kiadó. 136p., 86pl.

HABICHT, J.K.A. (1980) Paleoclimate, paleomagnetism and continental drift. AAPG Studies in Geology (9): $1-33,10$ maps.

JEFFERSON, T.H. (1982) Fossil forests from the lower Cretaceous of Alexander Island, Antártica. Paleontology, 25:681-708.

MAYER, L.M. (1986) Primeira ocorrência de Polysolenoxylon Krausel \& Dolianti na Formação Rio Bonito, Permiano, Bacia do Paraná. Anais da Academia Brasileira de Ciências, 58(3):509510.

MUSSA, D. (1982) Nova forma do Complexo Vertebraria nos argilitos carbonosos da Formação Rio Bonito, Santa Catarina, Brasil. Boletim - IG, 13:66-74.

PAGE, R. (1970) Dating episodes of faulting from tree-rings: effects of the 1958 rupture of the Fairweather-fault on tree grouth. Geological Society of America Bulletin, 81(10):30853094 .

PLUMSTEAD, E.P. (1973) The Late Paleozoic Glossopteris Flora. In: HALLAN, A., ed. Atlas of Palaeobiogeography. Amsterdam, Elsevier Scientific Publishing Co. p. 187-205.

ROSLER, O. (1975) Tafoflórulas eogondwânicas do Brasil. II - Ocorrência de Rio da Estiva (Permiano - Formação Rio Bonito - Santa Catarina). Boletim IG, 6:1-11.

ROSLER, O. (1978) The Brazilian eogondwanic floral succession. Boletim IG, 9:85-91.

SCHNEIDER, R.L.; MUHLMANN, H.; TOMMASI, E.; MEDEIROS, R.A.; DAEMON, R.F.; NOGUEIRA, A.A. (1974) Revisão estratigráfica da Bacia do Paraná. In: CONGRESSO BRASILEIRO DE GEOLOGIA, 27., Porto Alegre, 1974, Anais. Porto Alegre, Sociedade Brasileira de Geologia. V.1, 
p.41-65.

VOLKHEIMER, W. (1969) Palaeoclimatic evolution in Argentina and relations with other regions of Gondwana. In: IUGS SYMPOSIUM GONDWANA STRATIGRAPHY, Buenos Aires, 1967. Paris, Unesco. p.551-587.

Fig. 1 - Polysolenoxylon sp. (DGM 1.835-Pb). Seção transversal, mostrando borda medular com um canal secretor e parênquima, xilema primário centrífugo e lenho secundário adjacente. $(25 \mathrm{X})$.

Fig. 2 - Seção transversal (DGM 1.839-Pb). Passagem de lenho inicial para lenho final, mostrando limite de um anel verdadeiro (parte clara) e um "falso anel" (faixa escura). (63 X).

Fig. 3 - Seção transversal (MN 1.589-Pb). Passagem suave do lenho inicial para lenho final, limite de um anel verdadeiro. $(160 \mathrm{X})$. 

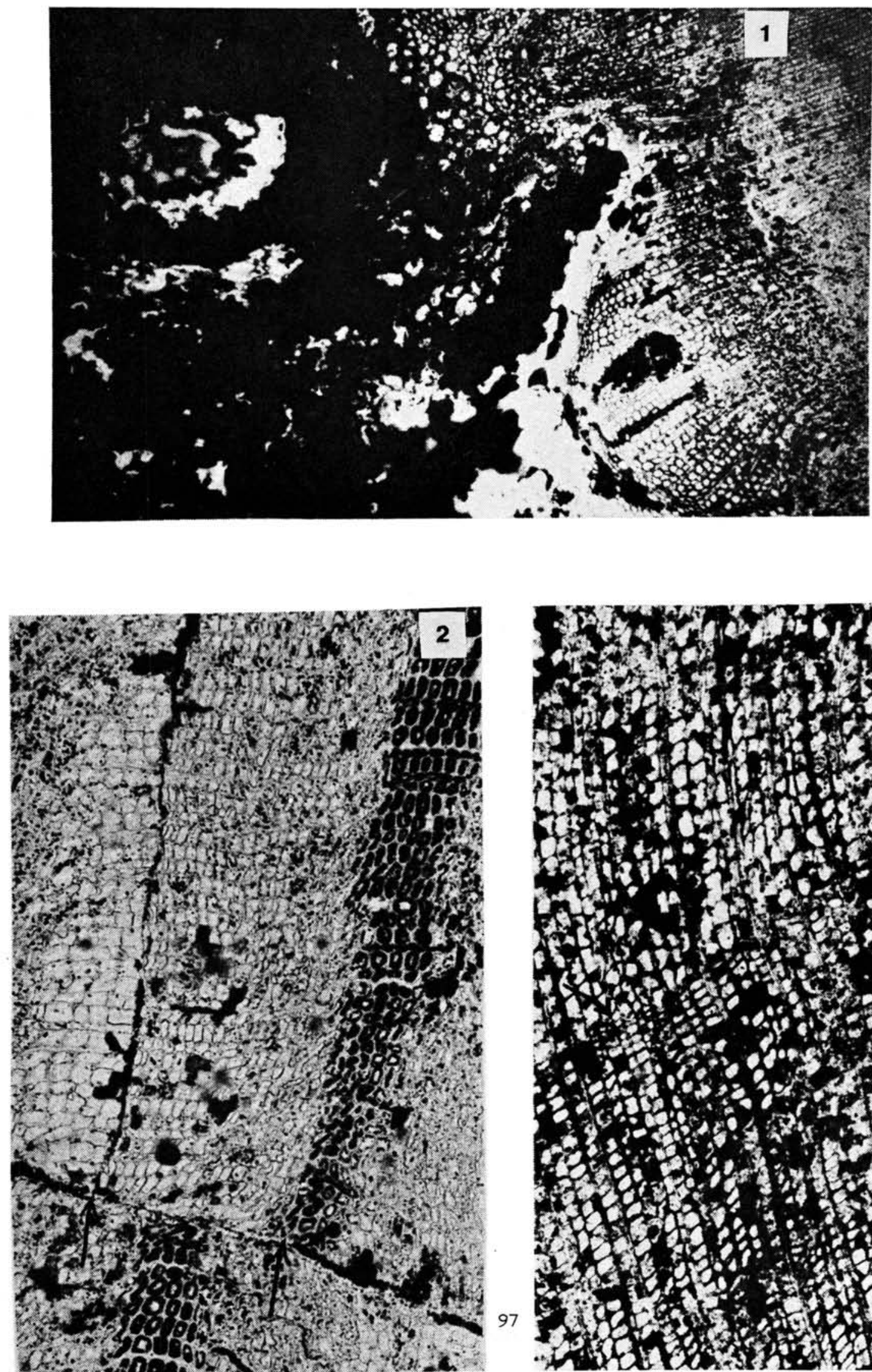

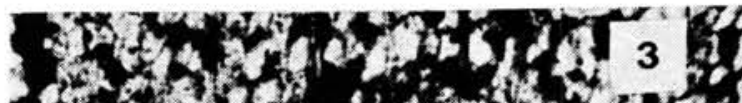

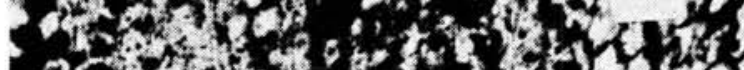

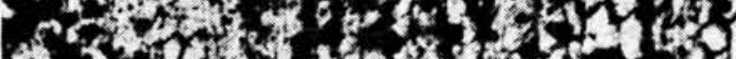
Het है।

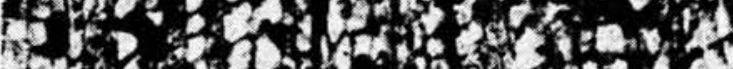

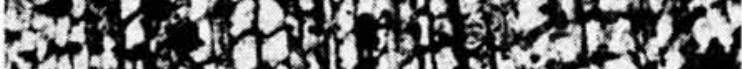

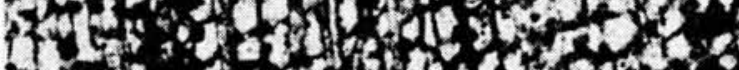

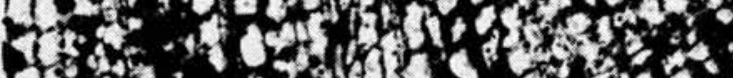

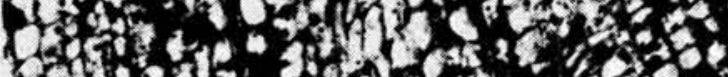

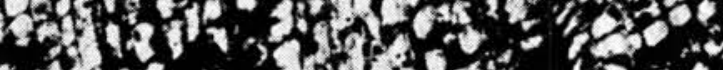

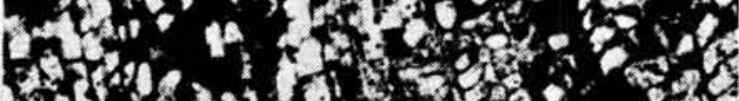

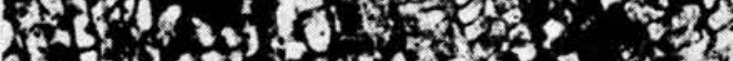
(5)

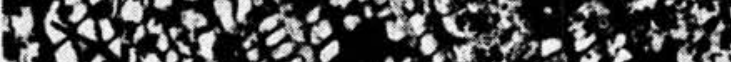

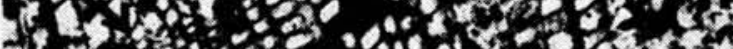

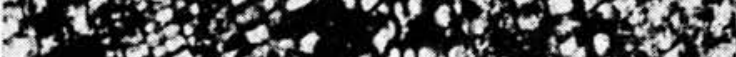

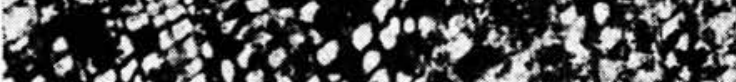

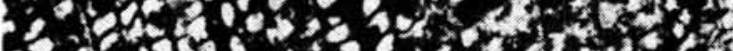
- Docotos a The 20 . 3fores

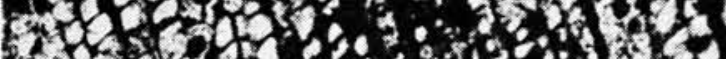

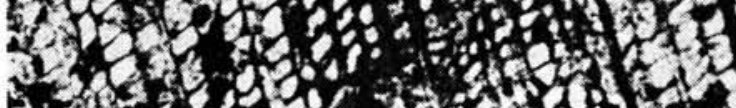

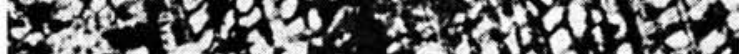

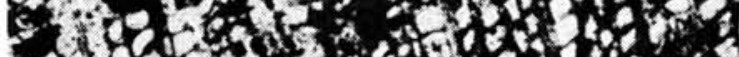

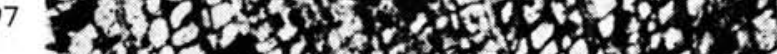
-1 of 
Fig. 1 - Polysolenoxylon sp. (MN 1.588-Pb). Seção radial. Xilema primário centrífugo, espessamentos espiralados, passando a escalariformes e reticulados. $(240 \mathrm{X})$.

Fig. 2 - Seção radial (DGM 1.839-Pb). Campo de cruzamento com pontuação "phyllocladóide". $(400 \mathrm{x})$.

Fig. 3 - Seção radial (MN 1.561-Pb). Paredes de traqueídeos com pontuações "araucarióides", do padrão mais comun a todos os exemplares. (250 X).

Fig. 4 - Seção tangencial (MN 1.562-Pb). Raios lenhosos uniseriados e baixos. (240 X). 
ESTAMPA II

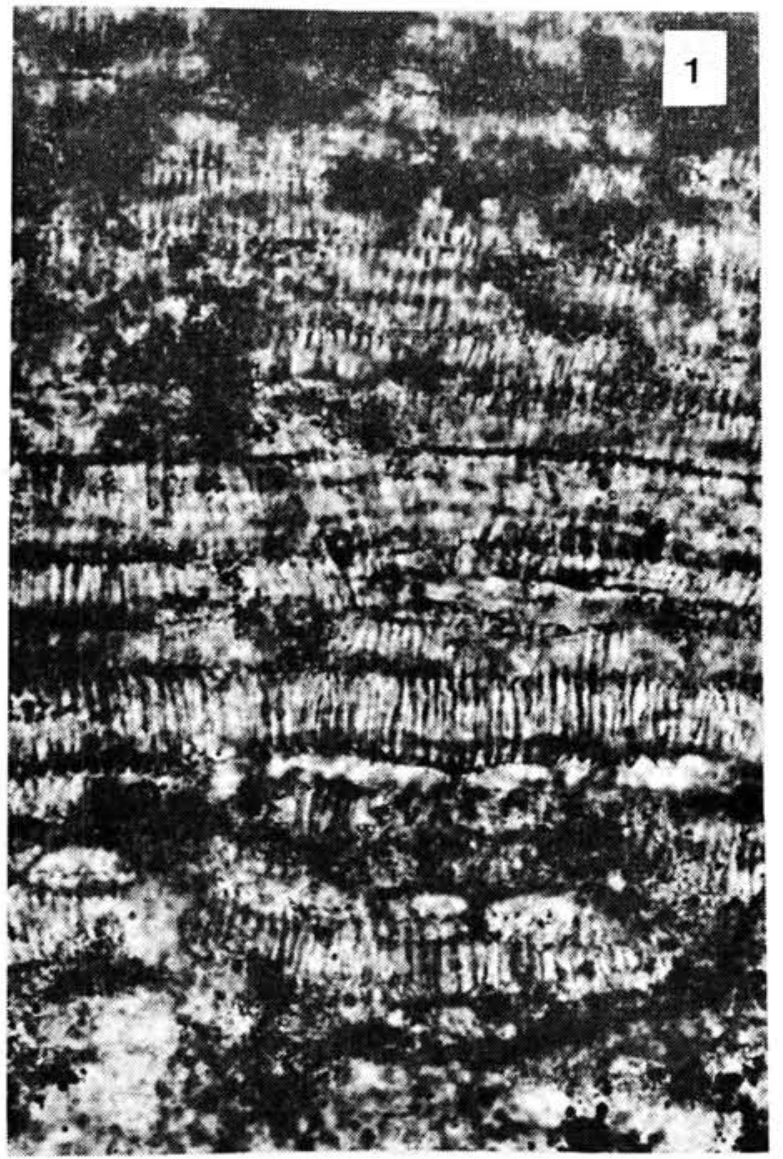

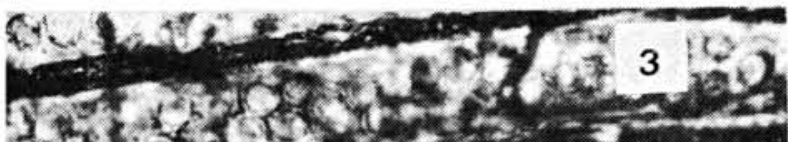
Mostors

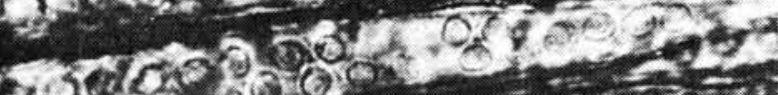
riseras

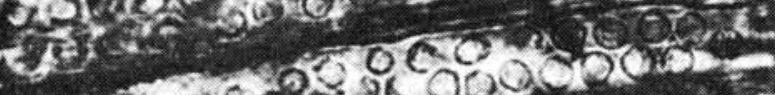

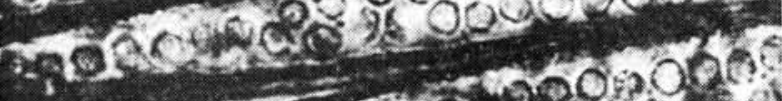

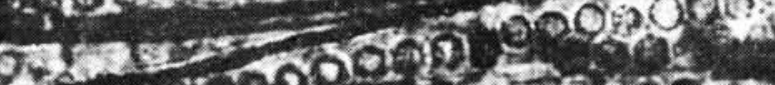

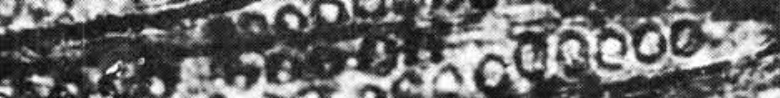

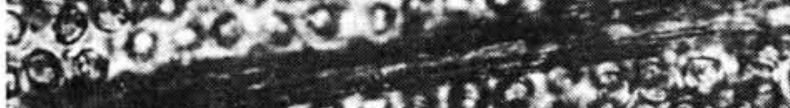

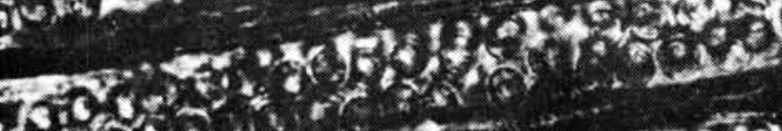

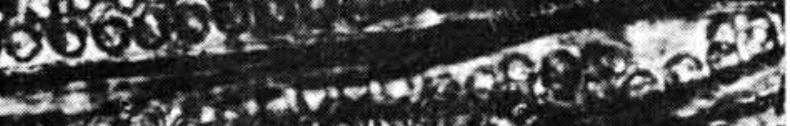

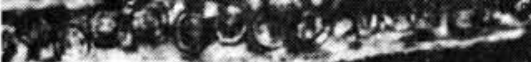

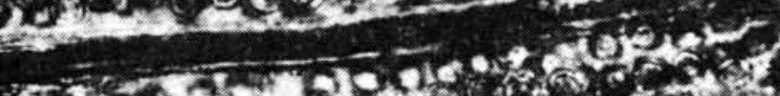

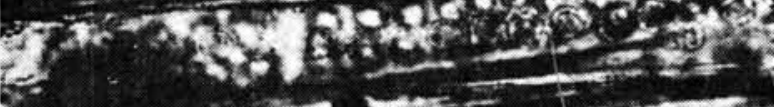
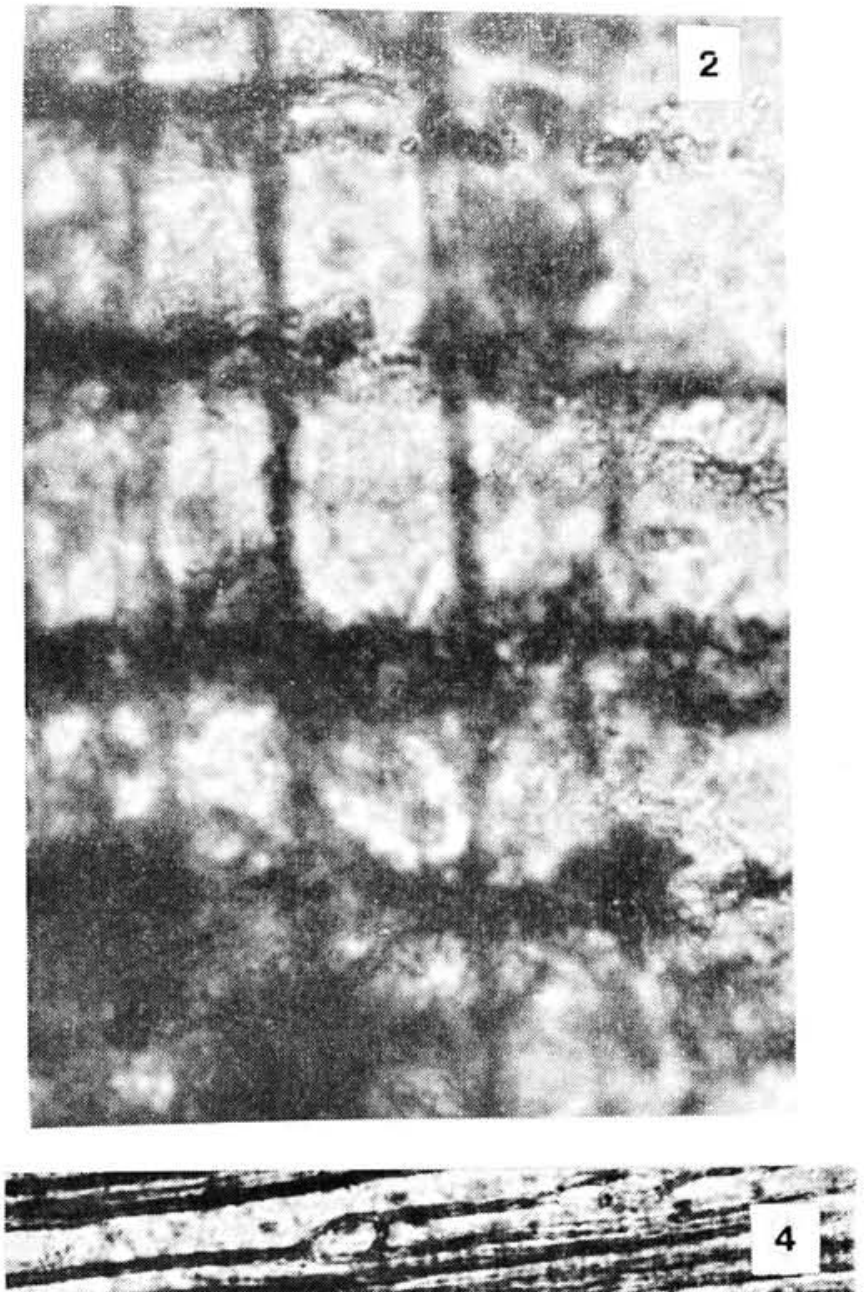

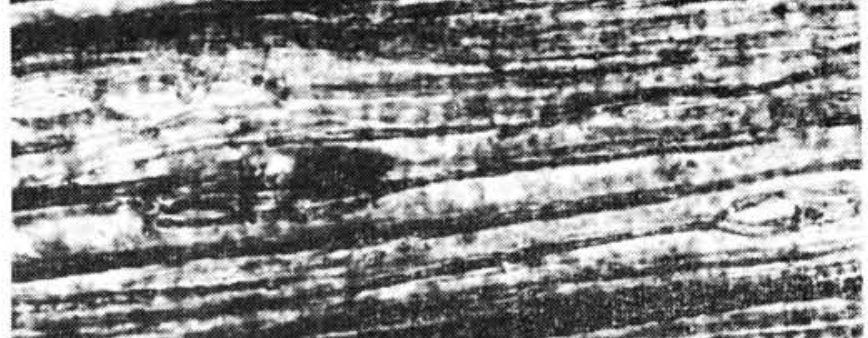

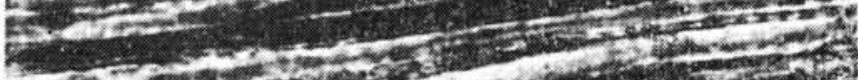

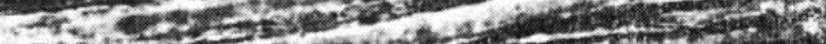

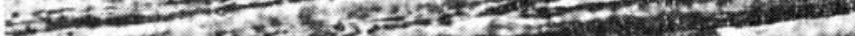

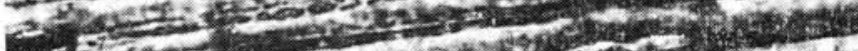

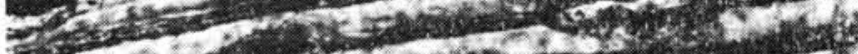

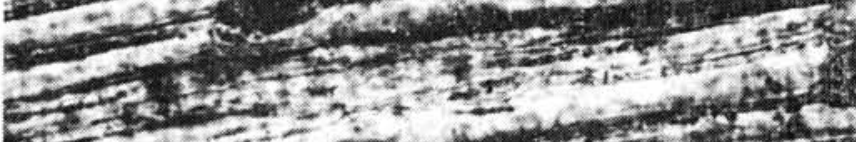

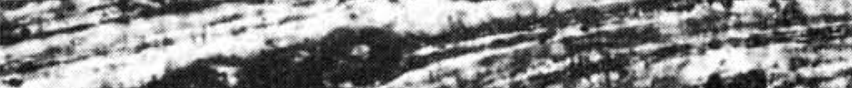

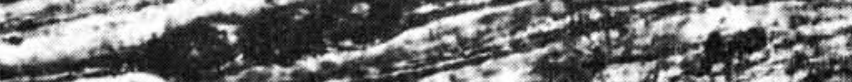

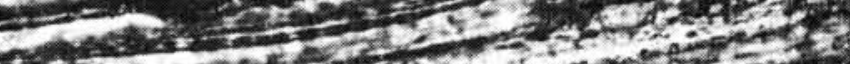

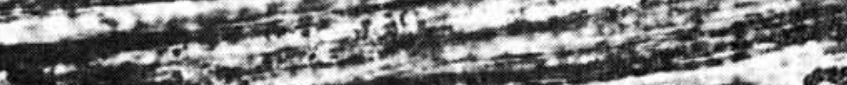

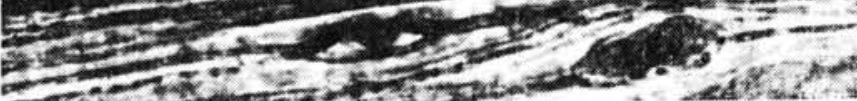

